\title{
Saudi Football Clubs Privatization Business Model
}

\author{
Prof. Issam Tlemsani (Corresponding author) \\ College of Business Administration, Prince Mohammad Bin Fahd University \\ P. O. Box 1664, Al-Khobar 31952, Kingdom of Saudi Arabia \\ E-mail: itlemsani@pmu.edu.sa \\ Saleh Al Sarraf \\ College of Business Administration, Prince Mohammad Bin Fahd University \\ P. O. Box 1664, Al-Khobar 31952, Kingdom of Saudi Arabia
}

Bader Alshowaier

College of Business Administration, Prince Mohammad Bin Fahd University

P. O. Box 1664, Al-Khobar 31952, Kingdom of Saudi Arabia

Mosaed Alotaibi

College of Business Administration, Prince Mohammad Bin Fahd University

P. O. Box 1664, Al-Khobar 31952, Kingdom of Saudi Arabia

\begin{abstract}
Ahmad Al Semari
College of Business Administration, Prince Mohammad Bin Fahd University P. O. Box 1664, Al-Khobar 31952, Kingdom of Saudi Arabia
\end{abstract}

Received: June 4, 2019

Accepted: June 27, 2019

Published: June 30, 2019

doi:10.5296/ijafr.v9i3.14929

URL: https://doi.org/10.5296/ijafr.v9i3.14929 


\section{MlMacrothink}

International Journal of Accounting and Financial Reporting

ISSN 2162-3082

2019, Vol. 9, No. 3

\section{Abstract}

This research is an attempt to explore possible solutions to the privatization of Saudi football clubs. It examines the business models of legendary internationally renowned football clubs i.e. Barcelona, Arsenal, Manchester City, and Juventus in order to select the best fit business model to implement in the Kingdom of Saudi Arabia. The strategic vision of KSA's 2030 is to privatize Saudi football clubs and detach them from any government involvement and make them financially independent like other successful international clubs. The purpose of this research is to provide a pathway to facilitate the Saudi Government's 2030 vision to diversify the Saudi economy, generate income and to establish multiple revenue streams for Saudi football clubs, so they can be fully independent and not rely on any support from the government.

In this research, we chose four successful international clubs; and analyze their business model. From there we chose the best fit business model that can be implemented into Saudi football clubs to start confidently when they privatize.

Keywords: Privatization, KSA economy, Saudi Arabia Vision 2030, Football clubs

\section{Introduction}

It is widely assumed that football is the most popular sport, the last world cup in 2018 had the highest number of views; according to FIFA the final match of the 2018 world cup had 1.12 billion people around the world watching it. In Saudi Arabia the Saudi Professional League was established in 1976. Historically, Saudi football clubs were financially supported by the government, and currently are supported by honorary members. One of the goals of Saudi Arabia 2030 vision is to privatize Saudi football clubs. According to senior staff in the chamber of commerce in KSA:

"With this decision, we are assured of switching sports institutions from full reliability to professionalism, more competitive sports, and a better future of sports organizations to create internal investment opportunities, contribute to the creation of permanent jobs, and help to stimulate physical activity and creativity to achieve sustainable development in sports to meet the public's aspirations and expectations" (Note 1).

Al-Ittihad was established in 1927 and is the first football club in Saudi Arabia followed by Al Ahli in 1937, Al-Shabab in 1947, Al-Nasser in 1955 and Al-Hilal established in 1957, these football clubs are the most popular clubs in Saudi Arabia. According to Saudi Arabia's 2030 vision of privatization:

"Some initiatives are scheduled to be finalized by 2020 (including sports clubs). These initiatives include privatization of both governments owned assets sale and PPP"

There are a number of reasons that the government decided to make privatization part of the 2030 vision; first, to reduce government spending on the clubs. Second, to make clubs financially independent like other successful clubs around the globe, such as; Barcelona, Arsenal, Manchester City, Juventus...etc. This research is an attempt to provide a pathway to facilitate Saudi Government's 2030 vision to diversify the Saudi economy, generate income 
and to establish multiple revenue streams for Saudi football clubs, so they can be fully independent and not depend on any government support. There are several football clubs internationally that have a very successful business model. Here we will focus on four successful football clubs; based on our analysis we selected the best fit business model for Saudi football clubs to achieve a successful privatization. Our primary reasons for selecting those four clubs were on their current financial position.

This paper is structured as followed: section (I) is a background to the subject and provides the aims, implications and purpose of this research. Section (II) provides the literature review of football clubs privatization. We examine four football clubs Barcelona, Arsenal, Manchester City, and Juventus and go along with an overview of Saudi football clubs in general. Section (III) describe the means of data collection and outlines the methodology in this research. Section (IV) describes analyses of the main revenue streams (ticket sales, television rights, player registration, and sales of product) of the most successful football clubs. Section (V) presents the result and critically evaluates the findings of this research and how to adopt a road map to privatized Saudi football clubs. Section (VI) contains the research conclusion.

\section{Literature Review}

We selected four football clubs (Barcelona, Manchester City, Arsenal, and Juventus) and each one of them has a different business models. Those selected clubs are financially independent and successful, by analyzing each football club's business model in detail it will help to identify a business model that is more appropriate to fit the Saudi Arabian football clubs privitizatition initiative.

\subsection{FC Barcelona}

F.C Barcelona was founded in 1899 by the Joan Gamber and a group of young foreigners living in Barcelona. According to the club; "Barcelona is living their golden era as they won every trophy possible, as no football club ever did (Note 2)". Their business model is based on reducing costs, they have an academy called FCBEscola that targets young talents between the ages of 6 and 18 years old, the purpose is to train them in a healthy environment, in order to prepare these talents to be the future players of the team, this can enhance their revenue as they will not be buying many expensive established football stars from other clubs. Barcelona's business model is effective for them. However, it will be difficult to implement in Saudi football clubs because of the lack of youth academies in the Saudi clubs. Also, the strategy for nurturing youth talents takes a long time to be adapted.

\subsection{Arsenal}

Arsenal was founded in 1886 by group of workers from Woolwich Arsenal Armament Factory. The business model that Arsenal uses is to nurture young talents (e.g. Van Persie, Samir Nasri, and Bacary Sagna) in one of the best academies. The idea is to sell players at the highest price to other clubs around the world, thereby increasing their revenue with the lowest possible cost of production; making financial performance their first priority. Arsenal's business model might work perfectly for them but it is also difficult to implement 


\section{Macrothink}

International Journal of Accounting and Financial Reporting

ISSN 2162-3082

2019, Vol. 9, No. 3

for Saudi football clubs because the idea of selling the best talents is not a favorable choice for Saudi football clubs since their priority is to be at the top on the pitch while balancing it with their financial performance.

\subsection{Manchester City}

The club was formed in 1880, under the name of St. Mark's. After calling themselves Gorton FC and Ardwick AFC for shorter periods, they changed their name to Manchester City in 1894. The club was close to financial disaster, struggling to pay wages and reduce debts, until Sheikh Mansour bin Zayed al-Nahyan bought the club in 2008 for £210 (Note 3) with a long-term strategy through a huge investment (£1.3 billion) supported by the government of Abu Dhabi as a diversification strategy to their economy by investing in well-known football clubs and players success. This business model is successful to the Manchester city club but it is not realistic to implement with Saudi clubs because this is an exceptional investment in the football industry.

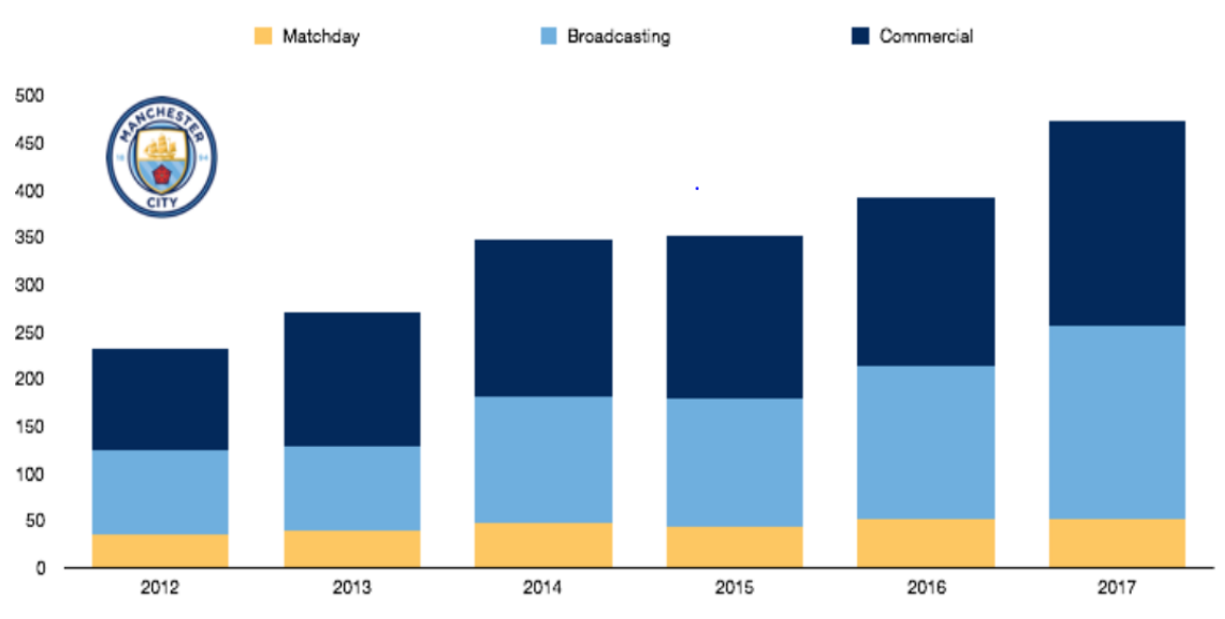

Figure 1. Manchester city revenue analysis

\subsection{Juventus}

The club was founded by a group of friends in 1897 and first started in the national championship in 1900. Juventus has been getting great results since the beginning and earned a lot of trophies during the 90s. On the contrary in 2006, one of the biggest scandal of Italian's football history occurred called "calciopoli" and Juventus was at the center of it. The Italian Football Federation found Juventus guilty of fixing matches after they won the Serie A championship of 2006, and was relegated to the Serie B, which is the league below the professional one. Juventus lost most of its valued players due to that punishment. In 2007, Juventus won the Serie B championship and were promoted to Serie A, but they struggled for two years to reestablish themselves after the calciopoli's scandal. In 2010, Juventus started to rise again under a new management team. Based on our findings we will consider Juventus' business model as the best fit to implement in order to privatize Saudi's football clubs. 


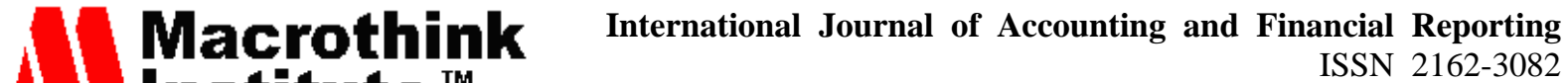 2019, Vol. 9, No. 3}

\subsection{Overview of Saudi Football Clubs}

Football in Kingdom of Saudi Arabia is one of a great source of happiness for the majority of the Saudi population. KSA has implemented 2030 vision and included many initiatives such as, privatization of the Saudi football clubs. However, Saudi football clubs are facing financial obstacles that hinder the privatization process. In order to achieve the privatization goal, the Saudi football clubs must pay off all of their debts first and become financially independent, their total debts in 2018 was SAR 961.6m (\$256.4m).

Table 1. Top five professional clubs net liability in Saudi Football League (in SAR)

\begin{tabular}{|c|c|c|c|c|c|c|c|}
\hline Club & Cash & litigation & Short Term Libality & Payable Salaries & Loans & Others & Total Liability \\
\hline Alitthad & $1,128.500$ & $.36,580,30$ & $-152,494,00$ & $.56,140.80$ & $.60,835.90$ & $-4,513,80$ & $.309,436,300$ \\
\hline Alnasser & $5,763.000$ & $-147,788.80$ & $-18,807.50$ & $-50,809.40$ & $.18,433.50$ & $-1,001.30$ & $231,077.500$ \\
\hline Alhilal & $1,546,400$ & $-30,374,90$ & $-35,290,00$ & $-37,637,70$ & $.10,107,00$ & $-3,621.30$ & $.115,484,500$ \\
\hline Alahli & $8,733.9$ & $-39,406,7$ & $-30,036.1$ & $-43,953.4$ & . & $-5,455.9$ & $.110,118.200$ \\
\hline Alshabab & $1,623.100$ & $-21,936,90$ & $-8,757,60$ & $-29,641.70$ & . & $-4,444,40$ & $-63,157,500$ \\
\hline Total & $18,794.900$ & $-276,087,60$ & $-245,385,20$ & $-218,183.00$ & $-89,376.40$ & $-19,036,70$ & $-829,274.000$ \\
\hline
\end{tabular}

\section{Research Methodology}

In this research, we gathered primary and secondary data. The primary data was gathered from interviewing people working in the Saudi football industry using a prepared themed questionnaire. Undertaking an interview was finest choice for the project to gather data, as the necessary data was not available to the public and can only be gathered through interviewing experts in that field. We developed four themes in our questionnaire the themes were convenient for the interviewees because it was structured based the four sources of revenue from the business model that we adopt.

Secondary data was gathered from several sources including the official source of the football clubs. The official 2030 vision document was collected to view the initiative of the privatization of the Saudi football clubs in the nearest future. Table 1 illustrate the net liability for the top five Saudi football clubs the data were taken from an article inside Sabq's website and it was translated from Arabic to English for the purpose of this research. Furthermore, we gathered the Juventus' income statement from 2005 to 2018 which provide a picture of their sources of revenue with its financial performances.

\section{Data Analysis and Discussion}

\subsection{Ticket Sales}

One of the main sources of revenue for clubs is the sales of tickets, according to Juventus's financial statement from 2005 to 2018 (please see appendix 1) the tickets sales are a large source of income in 2005/2006 was $€ 17.51 \mathrm{~m}$ and in 2006/2007 ticket sales were down by 


\section{MInstitute Macrothink $_{\text {Intion }}$}

International Journal of Accounting and Financial Reporting

ISSN 2162-3082

2019, Vol. 9, No. 3

$55.77 \%$ due to calciopoli's scandal in 2006. On average the next four years saw a straight increase in sales. In 2010/2011 the sales were $€ 11.55 \mathrm{~m}$, the biggest jump of revenue of sales was in $2011 / 2012$ an increase of $175.48 \%$ to the value of $€ 31.82 \mathrm{~m}$, this increase was because Juventus built their own stadium in that year. This gives us an indication of the value of owning a new stadium. In 2012/2013 the ticket sales were $€ 38.05 \mathrm{~m}$ and the following years there were a slight increase. Therefore, we can conclude that the stadium played a huge role as a source of revenue. The stadium's building cost Juventus $€ 155 \mathrm{~m}$. When each of the top five Saudi football clubs have their own stadiums, they will have the ability to have a main source of revenue. According to the General Sport Authority the top four clubs (Alhilal, Alnasser, Alittihad and Alahli) have to build their own stadium in the near future, and the fifth team (Alshabab) will rent King Saud University's Stadium. The time that it will take to build a stadium will depend on its size, capacity and the requirements of the General Sport Authority however, the top 4 football clubs which have the largest fan base will have to start building their own stadiums from 2020. The General Sport Authority will fund the cost of building the stadiums and in return it will receive all the amount of revenue until they recover the cost of the stadium, even if the club is privatized.

Table 2. Juventus' revenue (€ millions)

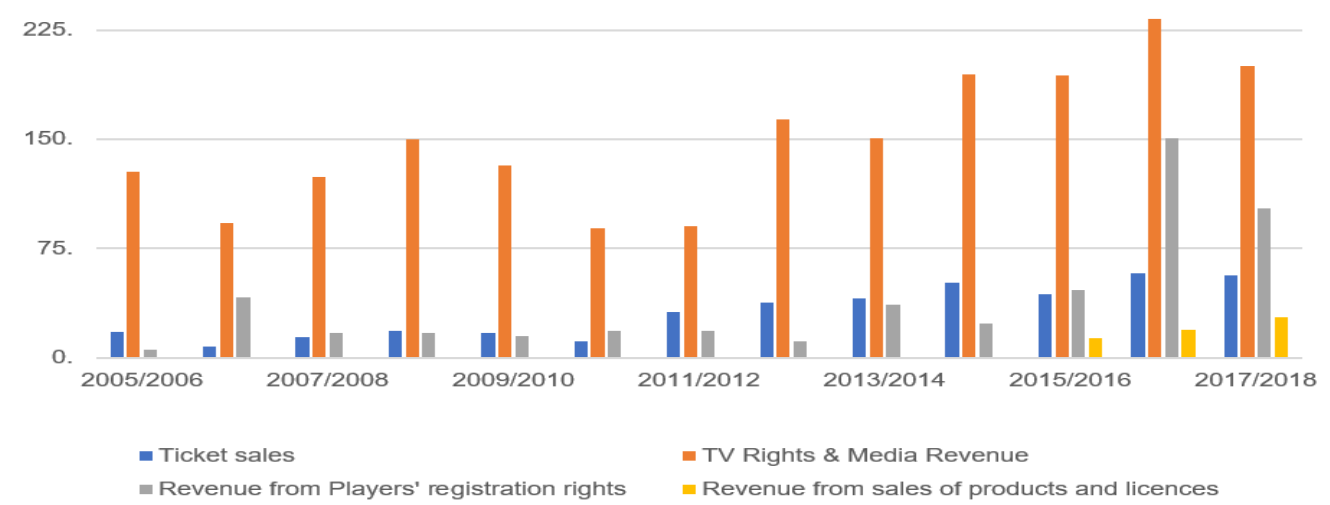

\subsection{Television Rights Revenue}

Television right is one of the biggest revenue streams for the most successful clubs in Europe. According to table 2 above television and radio rights represents the largest revenue stream for Juventus club. In the Italian league, television rights are distributed to the football clubs based on three parts: first, the historical ranking of the club; second, the ranking of the club over the past five years and thirdly; the ranking of the club in the present year. But the Italian minister of sports (Kooreasury) has changed the distribution of television rights in 2018/2019. The new distribution from television rights to the clubs is as follows: $50 \%$ of the revenue will be distributed equally to all Italian football clubs in Serie A, 30\% of the revenue will be distributed based on the football club's results, and $20 \%$ of the revenue will be distributed based on the popularity of the football clubs. As is shown in Juventus's financial statement (please see Appendix) in 2005/2006 their revenue from television rights was $€ 127.5 \mathrm{~m}$ however, dropped tremendously in the following season to $€ 93 \mathrm{~m}$ due to calciopoli's scandal. It surges in the following season to $€ 124.2 \mathrm{~m}$ due to their promotion to Serie A. In 
$2017 / 2018$ their income from television rights reached $€ 200 \mathrm{~m}$. The rise in revenue from television rights has increased greatly in the past five years because of the domestic competition and the European competition where Juventus was performing strongly in the Champions League. The Saudi Arabian Sport Federation will distribute the revenue as follows, $50 \%$ equally to all Saudi football clubs and the other $50 \%$ depends on the football clubs ranking in the current league.

\subsection{Sales of Products}

According to Juventus's financial statement from 2005 to 2018 the sales of products and licenses was not mentioned from 2005/2006 to 2013. According to Nikhil Srivastava:

"There's a catch: that price of $€ 40$ is the retail price of the kit. Most of the revenue from it goes to the manufacturer (which is why they agree to the huge sponsorship deals in the first place, as sponsorship of a football club essentially creates the right to sell their kits). The revenue is also shared between various shipping companies, and often the player himself (which is why image rights exist)"

However, in 2014/2015 the sales of products and licenses was $€ 13.5 \mathrm{~m}$ and in 2015/2016 it was $€ 19.2 \mathrm{~m}$, an increase of $42.10 \%$. Moreover, in $2017 / 2018$ the sales of products and licenses were $€ 27.8 \mathrm{~m}$. The sale of products includes $\mathrm{T}$-shirt, jackets, boots, pants etc. The licenses include giving the right to other external companies to produce products for example giving Adidas the right to produce the official match kit.

When Saudi clubs implement this model, it will be one of the main sources of revenue. However, when it comes to Saudi Arabia there must be regulations to prevent the sale of not genuine products. According to the General Sport Authority and Ministry of Commerce and Investment the General Sport Authority gives dealers the right to bring jerseys and products that is relevant to football clubs outside Saudi Arabia. However, when it comes to Saudi football clubs they have the responsibility to give dealers the right to sell their products. Moreover, when the clubs do not register their own logo as a trademark they lose the right to prevent reproducing their products. The football clubs have the right to build their stores and it is part of their investment. When clubs do not have multiple outlets for their merchandise and products they are considered not investing or developing effectively.

\subsection{Revenues from Players' Registration Rights}

Another large source of revenue for football club is the revenue from players' registration right, which is the right proceeds to receive from the sale of a federative right (registration right) for example; the right to receive transfer fees when transferring a player from one club to another. At first the revenue was only $€ 5.7 \mathrm{~m}$ in $2005 / 2006$. Over the next nine years the revenue has been steadily increasing, from approximately $€ 11 \mathrm{~m}$ to $€ 46 \mathrm{~m}$. The real significant change was in 2016/2017; when they gained a massive $€ 151 \mathrm{~m}$.

In the Saudi League, there is no focus on how to generate money from the player's registration rights. The main goal in KSA for young football players is to prepare them to be part of the first team from the academies, rather than spending millions on another player 
established at another club.

\section{Findings}

Based on our analysis Juventus's business model can be implemented in order to privatize the Saudi football clubs. Juventus's business model focuses on four main sources of revenue which are; sales of tickets, television rights, product sales and player registration rights. Most of these sources are already established in Saudi football clubs however, they are not used appropriately. We found that when Juventus built their own stadium, the number of ticket sales increased by $175 \%$ which is a big jump from their previous city's stadium. Therefore, we believe that when the General Sport Authority build stadiums for popular football clubs in Saudi Arabia, the stadiums would generate a source of revenue which will help them become financially fully independent. Therefore, the Saudi football clubs would not need governmental financial support in the long run as shown in table 1, which provides the debts of the most popular football clubs in KSA.

We found that the television rights are a major revenue stream for Juventus which will open the door for the Saudi football clubs to capture their potential income from television rights distribution. We found that the sales of products for Juventus are another important revenue streams. However, Saudi football clubs are not focusing on this piece due to the lack of stores around the KSA. In addition, the accessories of the football clubs are not being effectively used by the clubs to sell to the fans. Most importantly, when Saudi football clubs do not register their own logo, they do not have the right to sue any store that reproduces their products, which will affect their sales of products negatively.

Finally, another main source of revenue is player registration rights. Juventus focuses on buying free agent players, in which they would not pay any fees to the original club; they implement this strategy until they become financially able to buy football stars. On the other hand, Saudi football clubs have no clear strategy for buying and selling young talent and established players. This could impact their financial ability to buy a star player that will bring additional fans to the club and create more exposure on the international football map.

\section{Conclusion}

The purpose of this research is to provide a pathway to facilitate the Saudi Government's 2030 vision to diversify the Saudi economy, generate income and to establish multiple revenue streams for Saudi football clubs, so they can be fully independent and not rely on any support from the government. We analyzed four football clubs' business models (Barcelona, Arsenal, Manchester City, and Juventus) and we selected the Juventus business model as the best fit to be implemented in KSA to privatize the Saudi football clubs as Juventus' business model has diversified streams of revenue that will help Saudi football clubs be financially independent if it is implemented properly. This research was done to help the Saudi Government to reduce their cost on parenting Saudi clubs financially and achieve the initiatives of the 2030 vision. One major constraint in conducting this research is a lack of information/data as most of the information is governmental and this research could be a starting point for further research. 


\section{References}

Al Saud, A. (2019). An interview with the Head of General Sport Authority. Retrieved from https://www.youtube.com/watch?v=tL813yYqQdU\&feature=share

Anon. (2019). Retrieved from https://www.telegraph.co.uk/football/2017/05/03/juventus-went-back-became-European-heav yweights

Arab News. (2019). Privatization of sports clubs welcomed to bring quality shift in Saudi sports. Retrieved from http://www.arabnews.com/node/1014331/sports

FIFA World Cup Russia. (2018). Retrieved from https://www.fifa.com/worldcup/news/more-than-half-the-world-watched-record-breaking-20 18-world-cup

Financial Football News. (2019). Manchester City Financial Review 2018. Retrieved from http://financialfootballnews.com/manchester-city-financial-review-2018

Football Bloody Hell. (2019). From Calciopoli to signing Ronaldo. Juventus' rise from the ashes. Retrieved from https://footballbh.net/2018/08/04/juventus-rise-from-the-ashes-ronaldo

Fortune. (2019). Retrieved from http://fortune.com/2018/03/21/inside-fc-barcelona-global-football-empire

Hamad, M. (2019). Sports Authority announces the inventory of the debts of Saudi clubs for the period before the end of March 2018. Newspaper Sabd electronic. Retrieved from https://sabq.org/jTKLmY

$\begin{array}{llll}\text { Juventus.com. } & \text { (2019). } & \text { Retrieved }\end{array}$ http://www.juventus.com/media/native/investor-relations-docs/english/bilanci/1718/Relazion e\%20finanziaria\%20annuale\%20al\%2030\%20giugno\%202018_definitiva_ENG.pdf

Seligman, D. (2019). Merchandising and Licensing in Football - Carter Moore Solicitors, Manchester. Carter Moore Solicitors, Manchester. Retrieved from https://www.cmsolicitors.co.uk/news/sports-law/merchandising-licensing-football

Statista. (2019). Arsenal FC revenue segments 2008-2018. Statistic. Retrieved from https://www.statista.com/statistics/251152/revenue-of-fc-arsenal-london-by-stream/

Vision2030.gov.sa. (2019). Saudi Vision 2030. Privatization Program. Retrieved from https://www.vision2030.gov.sa/en/ncp

\section{Notes}

Note 1. Arabnews.com, 2016

Note 2. FC Barcelona, 2019

Note 3. https://en.wikipedia.org/wiki/Manchester_City_F.C._ownership_and_finances 


\section{Macrothink \\ International Journal of Accounting and Financial Reporting \\ ISSN 2162-3082 \\ 2019, Vol. 9, No. 3}

\section{Appendix: Juventus Income Statement}

\begin{tabular}{|c|c|c|c|c|c|c|c|c|c|c|c|c|c|}
\hline & & & & NOONE & STAPMERT" & & & & & & & & \\
\hline 60.0 & 20052006 & 20062007 & 20072008 & 20820009 & 2092010 & 20102011 & 20112012 & 20122013 & 20132014 & 2014015 & 20142015 & 20162017 & 20172018 \\
\hline & Fin & & & & & & & & & & & & \\
\hline Totats & 1759 & 1744 & 1390 & 18466 & 16900 & 1152 & 31324 & 3051 & $4 \%$ & 51369 & 43658 & 58.5 & 5440 \\
\hline 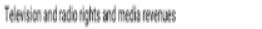 & 12,527 & 92966 & 12224 & 100139 & 1244 & MII & 925020 & 16968 & 10964 & 14211 & 19499 & $222 \pi 4$ & 20169 \\
\hline 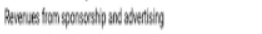 & 5540 & 3448 & 4.173 & 46133 & $466 \%$ & $42 \pi$ & 32452 & 5259 & 620 & 52755 & 70008 & 2479 & 86897 \\
\hline Reverus from seles of prodicts and licences & . & . & . & . & & & . & & & & 1350 & 1919 & 2797 \\
\hline 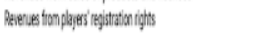 & 5115 & 415991 & $17: 10$ & 17211 & 14665 & 1839 & 18434 & 113 & 3641 & 2558 & 4604 & $151: 150$ & 10201 \\
\hline Oherereus & 19679 & 9917 & 1200 & 826 & 9915 & 1023 & 19:44. & 1827 & 20.91 & 24832 & 1944 & 20255 & 3995 \\
\hline TOTL REVENES & 260.02 & 186666 & 2017.73 & 20.134 & 2107932 & 172006 - & 2137866 & 208802. & 315728 & 3419 & 387901. & 52271 & 5060 \\
\hline 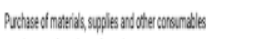 & (2815) & (3159) & 20.59 & $(230)$ & (226) & (2398) & (258) & (2BSA) & $(302)$ & (3100) & (3350) & (2880) & (3) \\
\hline Puchuses o d podedes for sole & ? & ? & ? & ? & ? & & . & & & & (434) & (B20) & (111/695) \\
\hline Btererd serices & $(37268)$ & $(2400)$ & $(20266)$ & (27) & $(272.25)$ & $(32: 40)$ & (401162) & (150079) & $(78606)$ & (15858) & (51:50) & 160598 & (76040) \\
\hline 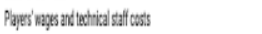 & (122087) & (50009) & $(112798)$ & $(122286)$ & $(127.055)$ & $\left.(12692)^{\prime}\right)$ & (181.1.24) & (HAMO) & (106887) & (172689) & $(197,16)$ & (205245) & [25250) \\
\hline Othepessent & (8005) & $(7878)$ & (81.12) & $(8078$ & (111:18) & (12788) & (12596) & (14:5s) & $(1620)$ & (19.991) & (20274) & (26462) & [26685] \\
\hline 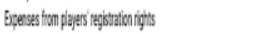 & (3112) & (1586) & (2178) & (2272) & (302) & $(16171)$ & (3287) & $(5580)$ & $(300)$ & $(\mathrm{DOM})$ & (10091) & $(520212)$ & (20100) \\
\hline Obte ass & $(28360)$ & $(40)$ & $(2076)$ & (2055) & 4919 & $(4006)$ & $(310)$ & $(10039)$ & (729) & (A3E) & (24ii) & (10.525) & (12229) \\
\hline 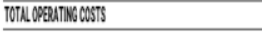 & $20660.64)$ & (1103997) & $(174,4)$ & {$[19(179)$} & $(1760685)$ & (1962:280) & $(26.319)$ & $(227.000)$ & $(266.613)$ & (263.855) & (30.094) & $(1006096)$ & (362.260) \\
\hline 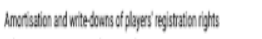 & $(5890)$ & (22765) & $(269)$ & (28033) & (3.4) & $(46745)$ & (523.6) & (5.4.15) & (50866) & (518:84 & $(6,047)$ & (2055) & (1079:954) \\
\hline 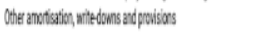 & $(2700)$ & (10055) & $(5986)$ & (4338) & $(2104)$ & (1915) & $(62)$ & $(M M)$ & (326) & (487) & (9.265) & (9998) & (12526) \\
\hline 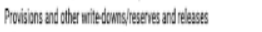 & & & & & & (111989) & 1040 & (bii) & (11262) & (465) & (1900) & $(2108)$ & (2SM) \\
\hline Othe now waringereus and costs & . & . & $(1991)$ & . & 213 & {$[3669$} & . & & & 1590 & 1069 & 30 & \\
\hline OPSQRTING NCOUE & $(19.65)$ & 600. & (10.201) & 1987. & 5220 & (92155) & $(41.14)$ & (3BS6]. & 8.846 & 19304 & 20214 & 61.377. & $(1,04$ \\
\hline Finncal nome & $1,1,98$ & 2881 & 3071 & 4186 & 354 & 1.68 & 1381 & 2354 & 3.192 & 2365 & 2400 & 4278 & 4261 \\
\hline Finxid enptices & (3) & (5114) & (41998) & $(455)$ & $(6727)$ & 2879 & (biti) & $(9,978)$ & (11181) & (10865) & (10355) & 11949. & 1169 \\
\hline 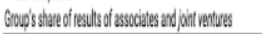 & . & . & . & . & . & . & ? & & & ? & $\mid 601)$ & 128. & 866 \\
\hline NCONE[LOCSS BEONETMES & (51.501) & 4186 & $(9,416)$ & 13,407 & 2076 & (98276) & $(159919)$ & $(10.915)$ & 167 & 10000 & 11600. & 88.15 & (100202) \\
\hline Crettars & (6697) & (1986) & 439 & (5556) & (3516) & $2786)$ & (27269) & $(5224)$ & (726) & $(7.989)$ & (4.65i) . & 1134. & $B 8 D$ \\
\hline Detrebtates & 1252 & $(1260)$ & $(7,0.2)$ & $(13001)$ & 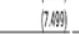 & 1.119 & 1.099 & 9 & 3 & (51) & 865. & 460. & 366 \\
\hline 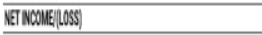 & $(145 \% 60)$ & (928) & $(20,78)$ & 6.52 & (10048) & (55:410) & $(18655)$ & (159911) & $(6679)$ & 2298 & 1062 & 12539- & (19:24) \\
\hline Garingy pes szan taxic) & (1080) & (Dovi) & (140) & 010 & (1008) & (14) & (OMP) & (1002) & and & 0002 & 0001 & OOMO & (2009) \\
\hline Earings ver shate (olited) & 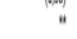 & (") & ( & $"$ & 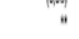 & ( & " & 4 & $"$ & $"$ & $"$ & $"$ & (4) \\
\hline STATEMENT OF COUPRESHESVENENCONE & & & & 20002008 & 20992010 & 20102011 & 20112012 & 2012013 & 20132014 & 20142015 & 2012015 & 20162017 & 20172018 \\
\hline Netinome (A) & & & & 6.592 & $(109888)$ & $(95444)$ & $(48665)$ & (15911) & (6674) & 2288 & 4.062 & 42568 & $(19229$ \\
\hline 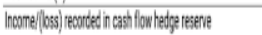 & & & & ? & (35) & 318 & $(721)$ & 128 & 179 & 235 & 218 & 1 & 1 \\
\hline 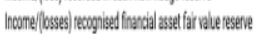 & & & & . & . & , & . & . & & , & 440 & (2065) & (2501) \\
\hline 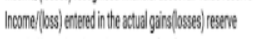 & & & & . & . & . & . & (122) & 569 & (44) & 18 & (128) & \\
\hline 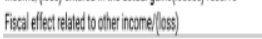 & & & & $\therefore$ & . & . & . & . & . & 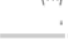 & . & . & \\
\hline 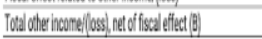 & & & & $\therefore$ & (357) & 318 & $(721)$ & (128) & (742) & 26 & $(4.749)$ & 2778 & 2501 \\
\hline COUPRESEISUENEIET NCONE(ABB) & & & & 6582 & $(113256)$ & $(859966)$ & $(49376)$ & (15911) & $(5902)$ & 2009 & 8811 & 40390 & $(21,730$ \\
\hline
\end{tabular}

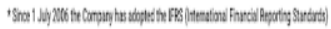

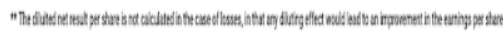

\section{Copyright Disclaimer}

Copyright for this article is retained by the author(s), with first publication rights granted to the journal.

This is an open-access article distributed under the terms and conditions of the Creative Commons Attribution license (http://creativecommons.org/licenses/by/4.0/) 